\title{
Briefing: The cultural life of public spaces
}

Lee Pugalis PhD, DipTP, MA, MTP, MRTPI, MIED, MeRSA

Senior Lecturer in Urban Theory and Practice, Northumbria University,

Newcastle, UK

Within a UK context of radical policy reform and broader global economic shifts, the homogenisation of public space and the decimation of cultural life are leading-edge issues of contemporary concern. Drawing on empirics from a broader research project, this briefing paper reports on the (ongoing) production of public spaces and extracts some pointers for practice pertaining to planning for their cultural life. Underutilisation, temporal dimensions and perceptions of urban quality are analysed, before tentatively considering future directions. Multi-stakeholder coproduction is put forward as a potentially fruitful mode of working.

\section{Introduction}

As UK policy continues to promote economic competitiveness most recently by way of the coalition government's drive to rebalance the economy in favour of the private sector paradoxically the vibrancy of many public spaces appears to be rescinding. Indeed, with public sector budget cuts disproportionately impacting the shaping of places, concern is mounting that public policy activity to support the thriving cultural life of public spaces may be neglected in the present age of austerity. More so, even in the good old days - in the decade preceding the global credit crisis - signs pertaining to the homogenisation of public space and the decimation of cultural life became clearer. The overly simplistic practice of utilising a standard 'toolbox' of measures and the importation of a contemporary cultural aesthetic has been widely lambasted for eroding the uniqueness of public spaces, including the disposition of everyday users to make way for a choice clientele of consumers. This briefing derives from a research project, 'Public space vitality in the North East', undertaken in 2005/06 by a multidisciplinary team based at Newcastle University, which the author participated in (see Pugalis, 2009a, 2009b). Additional research was undertaken by the author in 2008 and 2010 to address some of the original research limitations, such as the temporal dimension of space, and refresh the analysis in respect of the change in economic climate.

\section{Research objectives and approach}

With regard to public spaces, the study analysed how a multiplicity of stakeholders (transcending public-private-community interests) could collectively work together to support a broader range of public experiences, cultural interactions and economic activities, and how planning for public space could promote rather than preclude the cultural life of towns and cities. Taking a case study approach, the research investigated a range of public space typologies within towns and cities geographically distributed across the North East of England, including squares, promenades, high streets and market places considered to be of cultural and economic prominence within their own localities (Figure 1 and Table 1). The sites of study were Alnwick Market Place, Durham Millennium Square, Redcar Esplanade, Stockton High Street and the adjoining sites of Newcastle Monument and Old Eldon Square. Qualitative material was gathered from face-to-face interviews with those who have a 'stake' or responsibility in the planning, design, funding, management and/or governance of public spaces, and supplemented with on-site investigations including engagement with public space users and everyday producers. In addition to 18 interviews conducted by the research team in 2005/06, a minimum of five interviews across each of the five sites were conducted by the author. These typically included town centre managers, planning officers, retail and business representatives, regeneration practitioners and urban designers.

\section{Cultural and economic vitality}

Scratching beneath the surface, in-depth explorations of the five sites of study revealed that everyday cultural life is thriving in many of these spaces but nonetheless a cluster of concerns is discernible. Perhaps with the exception of Monument-Old Eldon Square in Newcastle, stakeholder and public perceptions converged in their assessment, which deemed each space to be socially and economically underutilised. Considering that each space had recently undergone variable forms of place quality interventions, ranging from streetscape enhancements to managed programmes of events, this finding has both positive and negative connotations. On a positive aspect, it could be deduced that the hard and/or soft place quality interventions had created an environment or stage conducive to socio-economic activity and cultural life. Less positively, the perception that the majority of the sites remained underutilised indicates that interventions had only partially delivered on either potential or promise. 


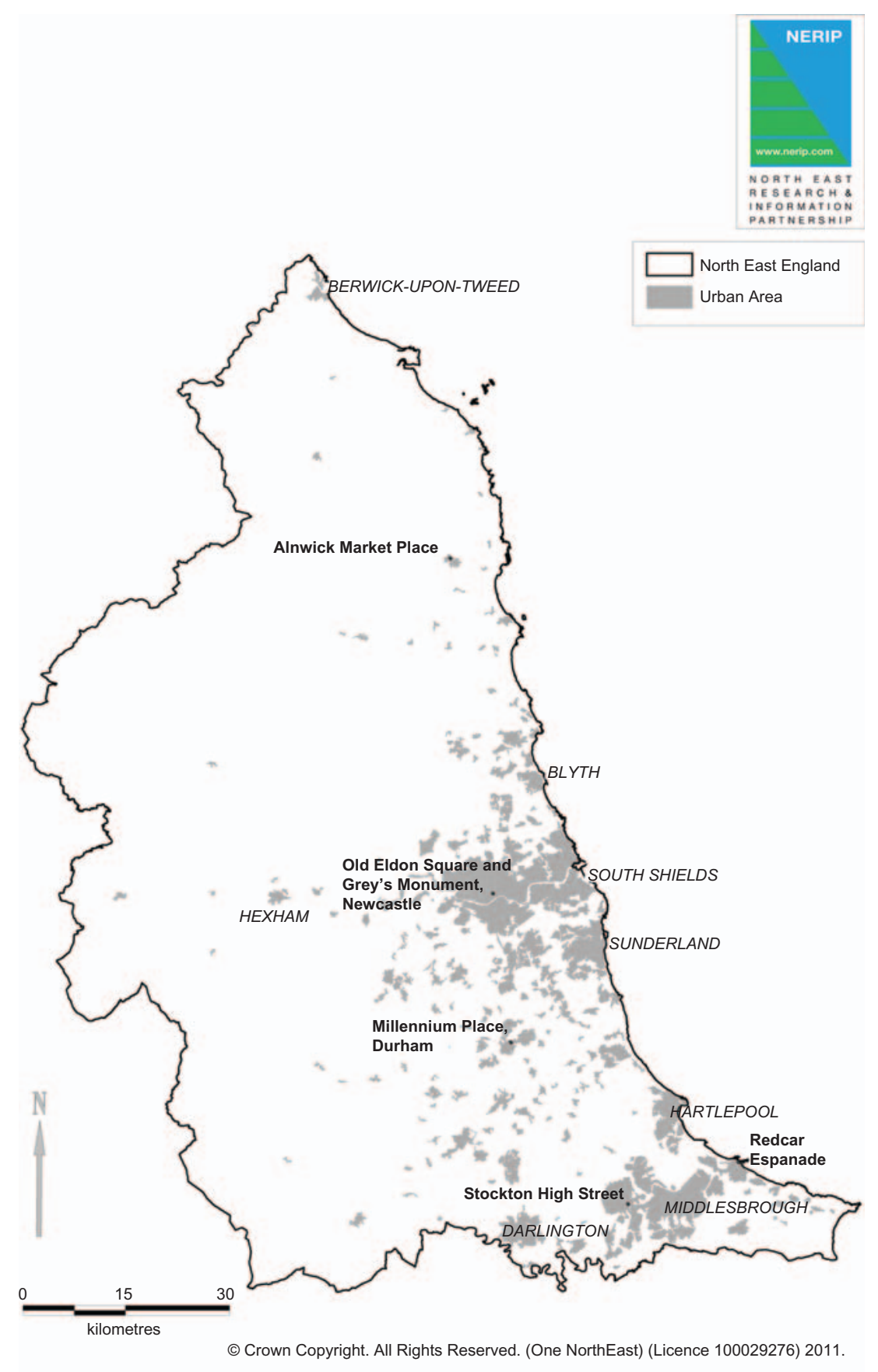

Figure 1. Case study locations

Direct observations support these opinions, where empty commercial units and socially leftover space were arguably the most noticeable aspects of underutilisation.

The temporal dimension was also an important factor in the underutilisation of public space. Durham Millennium Square, for example, 'came to life after dark' noted one user, but was less active during daytime hours. During the day, Millennium Square's primary role was that of appearance rather than experience. The study found that one-off or intermittent events, producing moments of energised space, help to punctuate the banality of everyday cultural life. Yet, these 


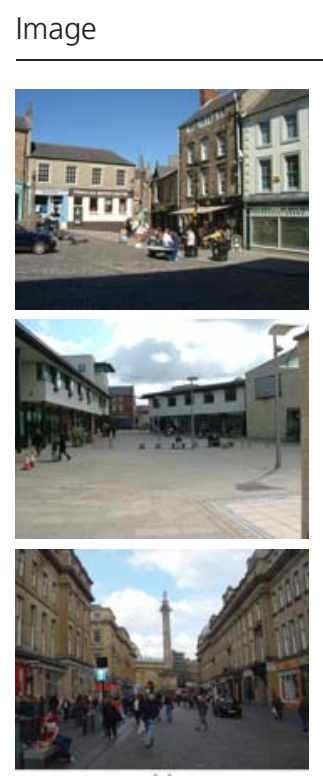

(a)

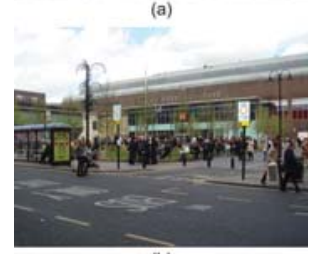

(b)
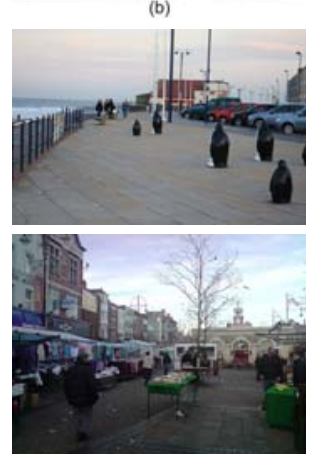

Location Description

Alnwick, Northumberland

Pedestrianised area surrounded by historic buildings with a strong sense of place, situated in the core of a market town setting.

Millennium Place Durham city

Old Eldon Square and Grey's Newcastle-uponMonument Tyne

Forms the 'heart' of the regional capital, displaying huge symbolic and cultural meaning and creating a legible space.
Contemporary space conveying a sober aesthetic. High-quality materials used but currently detached from surroundings.
The Esplanade

High Street
Redcar, Cleveland

Stockton-on-Tees

Table 1. Summary of study sites

situations of vitality tend to accentuate the underutilisation or latent potential of public spaces 'the rest of the time', which was particularly noticeable in Stockton High Street on nonmarket days. From this, it can be inferred that situations of vitality help raise the bar in terms of interest and expectations, which has positive cultural and economic implications. However, if this is not carefully managed then opportunities can quickly pass. More problematic, bypassed opportunities can foster negative perceptions that the space is rarely functioning at its optimum. Analysing the cultural life of public spaces through a temporal lens draws attention to a key policy dilemma: situations of vitality, generally lauded as 'successes', can generate issues downstream if the temporal rhythms (i.e. daily, weekly, seasonal etc.) and longer-term functionality of the space is not adequately considered.

Research participants bemoaned the 'twilight' hours between the end of the traditional working day when shops tend to close and the transition to an evening economy, which is a common issue faced by many prominent public spaces in England, but less so of an issue in many other countries, such as Spain or the Netherlands. Traffic was also considered to be a major impediment to vibrancy, but contrary to the views held by some retailers prior to place quality enhancements, postintervention stakeholder views supported by a limited amount of financial data indicated that pedestrianisation can increase 
Urban Design and Planning

Volume 166 Issue DP3
Briefing: The cultural life of

public spaces

Pugalis trade and capital values. Nevertheless, blanket pedestrianisation is not called for; traffic and accessibility considerations require sensitive management that can be helped if spaces are flexible: adapting to the ebbs and flows of cultural-economic life.

In terms of urban quality a consistent picture emerged: professional stakeholders tended to be more preoccupied with design details and the process informing the form of public spaces, whereas users tended to only comment on design aspects in terms of deficiencies. This was a surprising finding considering that each space varies in terms of typology, urban form, architecture and materials. Therefore, relative user silence on aesthetics and designscapes should not necessarily be used by practitioners as 'evidence' that some form of intervention or design improvements is required - providing the automatic 'fix' to reinvigorate the cultural life of public spaces. Rather, design silence can often indicate that the urban stage is performing well: facilitating cultural interactions and economic exchanges in an unassuming manner. On the converse, substandard design quality or deficient maintenance was perceived by the everyday user to be a considerable detractor, which also affects perceptions of safety. Hence, while urban quality can go relatively unnoticed, a lack of quality can be significantly detrimental to the cultural and economic vitality of public spaces.

An impression emerged from stakeholders and users that the production of public spaces is a continual process - an uneven development trajectory where the cultural life and economic vibrancy of a place was continuously being made and remade. Such a dynamic process that seeps beyond the control of formalised hard and soft interventions to encompass the everyday actions, contests and struggles of users (and therefore producers) raises some fundamental issues for traditional practice. Whether it be streetscape improvements, events, building refurbishments or broader regeneration strategies, each tends to be formulated as a project with a programme of key milestones and consequently a completion date. Therefore, conceptualising the production of public space as a continuous process is a challenging notion to grapple with in practice, not least because of financial perspectives that would crudely deem such ongoing commitments as a 'liability'. This finding is particularly significant in the context of ongoing policy fixes, shifts in political direction and time-limited funding streams.

\section{Pointers for practice}

A series of pointers for practice emerged from the research specific to the spatial planning and design of the cultural life of public spaces (detailed in Pugalis, 2009b: p. 227). A clear picture materialised that no single profession or community of interest can stake an exclusive claim to 'leading' the (ongoing) production of the cultural life of public spaces. Creative interaction between users, designers, project developers and management practitioners may help bridge the professional 'blind fields' and draw on the local knowledge and expertise accumulated by inhabitants and businesses. Creative interaction between diverse communities of practice should not diminish the role of the professions, but instead, challenge them to work within a culturally sensitive community framework promoting economically active urban space. Perhaps such a form of coproduction may evolve from the Coalition Government's 'Big society' ideal, although the jury is still out.

Urban quality appears crucial for all public space interventions, in terms of materials, maintenance and management. There is a danger, which is particularly acute in the present economic climate of fiscal austerity, that quality is viewed as an overhead that can be shaved-off development costs. Taking such a tactic bears all the hallmarks of knowing the price of everything and the value of nothing. Viewing quality as a luxury or 'add-on' is likely to hinder the cultural vivacity and economic exuberance of places. Further, it is conceivable that short-term project 'wins' will come with longer-term social regenerative 'costs'. It would also appear that management programmes are required that maximise the economic and cultural benefits of investing in 'hardware', such as streetscape improvements, with the 'software' of planned and unplanned activities. It is the latter dimension of the cultural life of public spaces, the software, that practitioners, particularly in the design/ planning field, often overlook. Perhaps the most important pointer for practice is the need to build in flexibility producing loose, mutable spaces that accommodate difference. Keeping spaces 'open' in the sense that they are physically, socially, economically and symbolically accessible would help adapt to a changing cultural life. Yet, this is likely to prove challenging in the face of complex legislation, ownership and bureaucratic processes, which reinforces the need for multi-stakeholder coproduction.

\section{Future directions}

A symbiotic relationship exists between cultural animation and economic activity: each reinforces the other and collectively contributes to the cultural life of public spaces. In times of economic hardship an economic competitiveness discourse is likely to penetrate deeper into the decision-makers psyche; as 'doing more with less' becomes the new mantra. Reconciling economic targets and community objectives by way of planning for the cultural life of public spaces in a locally sensitive and inclusive manner may help policy-makers, practitioners and developers locate that 'competitive edge' they characteristically desire.

At a crucial juncture when the English planning system is about to embark on yet another round of fundamental reforms, a hesitant global economic outlook and almost 
unprecedented public sector spending reductions, the termination of a large swathe of regeneration programmes, and the concomitant loss of human capital; predicting the future directions of the production of public space would be a tricky task. Perhaps this situation will help rebalance public-privatecommunity relations and open the door for the coproduction of public space? More strategically, is there a role for local enterprise partnerships, devised by the Coalition as the new managerial 'fix', to provide the spatial governance arena to reconcile such issues and champion the cultural life and shaping of places at the sub-national level? As this policy story is still being (re)written, the future direction remains a befuddled narrative, but the implications for the governance, planning, design and cultural production of public spaces may be profound.

\section{REFERENCES}

Pugalis L (2009a) Cultural animation and economic vitality: identifying the links and regeneration potential through the lens of the urban street scene. Journal of Urban Regeneration and Renewal 3(1): 7-19.

Pugalis L (2009b) The culture and economics of urban public space design: public and professional perceptions. Urban Design International 14(4): 215-230.

\section{WHAT DO YOU THINK?}

To discuss this briefing, please email up to 500 words to the editor at journals@ice.org.uk. Your contribution will be forwarded to the author(s) for a reply and, if considered appropriate by the editorial panel, will be published as discussion in a future issue of the journal.

Proceedings journals rely entirely on contributions sent in by civil engineering professionals, academics and students. Papers should be 2000-5000 words long (briefing papers should be 1000-2000 words long), with adequate illustrations and references. You can submit your paper online via www.icevirtuallibrary.com/content/journals, where you will also find detailed author guidelines. 